\title{
Application of GIS technologies in quality management of land accounting in Uzbekistan
}

\author{
Aziz Inamov ${ }^{1, *}$, Nilufar Avilova ${ }^{1}$, Dilshoda Norbaeva $^{1}$, Shakhnoza Mukhammadayubova ${ }^{1}$, \\ Maftuna Idirova ${ }^{1}$, and Jakhongirmirzo Vakhobov ${ }^{1}$ \\ ${ }^{1}$ Tashkent Institute of Irrigation and Agricultural Mechanization Engineers, Kari Niyazi str., 39, \\ Tashkent, 100000, Uzbekistan
}

\begin{abstract}
Qualitative land accounting plays an important role in the efficient use of agricultural land, the targeted placement of crops and the imposition of taxes on land users. Today, the quality of irrigated agricultural land shows the use of traditional methods in determining, assessing and mapping is inefficient in terms of time and cost. This, in turn, increases the need for fast, resource-efficient and science-based methods of modern geographic information system (GIS) technologies to address these issues. This article describes the results of scientific research on the compilation of histogram maps of soil quality indicators and geostatistical analysis using GIS technologies to determine the quality of irrigated agricultural lands. Hereby, the quality of soils was mapped in an automated system using the method of quality colors, the results of geostatistical analysis were converted into cartographic data and a new scale of values was developed. Geostatic analysis was performed in ArcGIS based on agrochemical cartogram data of land contours.
\end{abstract}

\section{Introduction}

In the world and in its different provinces, the automation of monitoring, accounting and qualitative assessment of agricultural lands is of particular importance [1,10]. Therefore, one of the important issues is the establishment of control over the use of irrigated lands and the maintenance of an automated system of land accounting in the geographic database. In this regard, including the United Kingdom, France, Germany, the Netherlands, Italy, the United States and other developed countries, the important scientific-practical issues of agricultural land accounting, land cadastre database creation and automation of land information generation systems are paid particular attention in the field of land management and land cadastre [1-3].

Targeted research aimed at determining the quality of agricultural land in the world, conducting regime observations on stationary and semi-stationary ecological areas using modern methods of research, innovative methods of agricultural land accounting and integration of field research into geographic database and modularization of automated systems research is of particular importance. One of the important tasks in this area, in

\footnotetext{
* Corresponding author: aziz.inamovg@gmail.com
} 
particular, is the automation and modularization of the geographic database management system of irrigated lands of Uzbekistan $[4,5]$.

In the context of irrigated agriculture, the quality of soils is constantly changing. Under the influence of human economic activity, due to the improvement of land reclamation, the level of their fertility and quality can also increase. Herein, only the stable and unstable features of the soils should be taken into account. Stable features (mechanical content, amount of humus) can change over a long period of time under the influence of irrigation. However, unstable features (salinity, nutrient availability, etc.) can change rapidly under the influence of human economic activity [6-9].

In 2017, soil research monitoring was carried out in 45 stationary ecological and semistationary ecological areas selected from 15 key areas (KA) per hectare selected from Jizzakh province of Uzbekistan. As a result, soil maps of irrigated agricultural lands were created. Soil maps of these irrigated agricultural lands were created using ArcGIS software. These works were carried out in Ak Altin of Sh. Rashidov district of Jizzakh province, Aktash of Gallaaral district, Mugal of Bakhmal district, Bulakbashi of Forish district, Kahramon of Dustlik district, Mingchinor of Pakhtakor district, Yangiyul of Mirzachul district, Dustlik of Arnasay district, Khulkar of Zafarabad district, Andijan of Zarbdor district, Chilanzar of Zomin district and in other adjacent massifs of the district. The data of soil cover and chemical analysis of the selected stationary ecological and semi-stationary ecological areas were studied in comparison with the results of the previous study $[1,3$, $11]$.

In this regard, European scientists J.A. Buryak, F.N. Lisetskiy, O.A. Marininas in their scientific article "Geostatistical analysis of agro-industrial zones of agricultural lands using GIS-technologies" focused on the widespread use of improved geoinformation and agrochemical research using computer technology, geoinformation modeling and remote zoning data to solve a number of methodological problems and obtain qualitatively new results and have done successful work. It has also been pointed out that the structural features of soils or their combinations can be based on indicators that allow for the objective identification of repetitive and different areas [1, 3, 5, 12].

Based on the above, the purpose of the scientific article is to digitize information about land types, arable land, land users and land accounting in geo-information system programs, as well as to automate and modulate the system of calculating the normative value of land, based on algorithms [1, 13]. As a scientific novelty of this work, the method of integrated digital mapping of soil maps has been improved on the basis of GPS and geodata, land navigation has been improved on the basis of GPS Mobile Mapper, ArcGIS has improved the method of land accounting and soil mapping on the basis of Model Builder's algorithmic system can be shown.

\section{Materials and methods}

The research used methods such as land accounting, monitoring, geostatistical analysis, geo-spatial linking of objects, mapping, algorithms, coding and digitization of information. While the program previously created 1:10,000 scale electronic digital maps of agriculture based on remote zoning materials, data such as land types, land contours, land monitoring results, and land users were entered into the electronic digital map using ArcGIS software.

The results of field research on soil analysis were determined using a GPS device to determine the coordinates of the incision and integrated into a geodata database. As a result of geostatistical analysis of coordinate values, soil allotments were created that visualize soil quality soil quality indices.

According to the results of the field research, the development of normative value indicators in an automated system was carried out on the basis of the integration of 
information on the values determined by land accounting and soil quality soil quality indices.

\section{Results and discussion}

The results of soil assessment showed that in almost all districts of Jizzakh province have changed over the past 20 years as a result of reclamation measures, the average soil quality index of irrigated lands in Jizzakh province in 2019 amounted to 51 points. This figure was 50 points in 1999. The district-wide analyzes are shown below in the histogram Fig. 1.

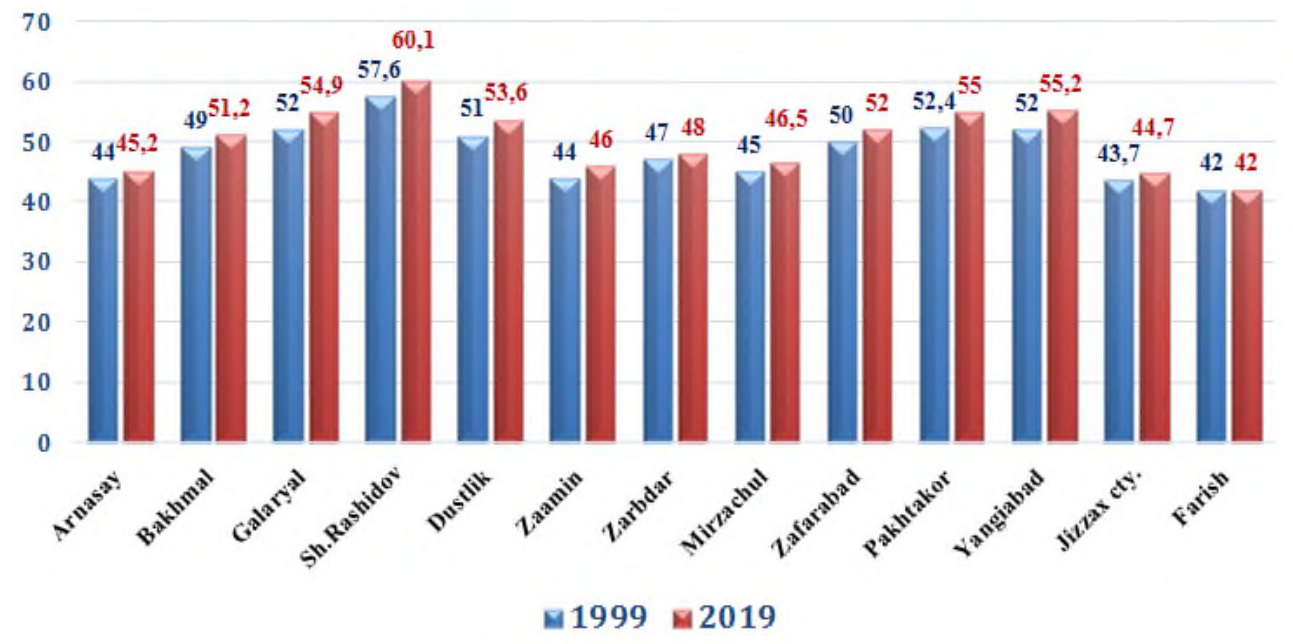

Fig. 1. Histogram of growth of 20-year soil quality index points in the districts of Jizzakh province.

In soil monitoring studies conducted in 2017, low-humus (up to $1.0 \%$ ) lands in irrigated soils accounted for $51.5 \%, 47.0 \%$ of average (above 1.0 percent) and $1.5 \%$ of adequate lands. $51.5 \%$ of the total irrigated lands were found to be low in humus, and these areas were recorded in the main agricultural lands with irrigated hydromorphic soils in Mirzachul, Arnasay, Zafarabad and Zarbdor districts in the north of the province.

Despite the fact that Uzbekistan's irrigated soils are low in humus by nature, they play an important role in soil productivity. The main way to enrich soils with humus and nutrients is to applgy organic and mineral fertilizers, taking into account soil conditions and crop requirements [3-5].

In order to visualize and geostatistically analyze the quality indicators of agricultural lands in ArcGIS software belonging to the family of geoinformation systems, the authors developed a special methodology for integrating information on soil quality index score, one of the quality indicators of lands, into a geodata using innovative technologies (Fig. 2).

The stages of compiling a histogram of soil allotments of land contours and geostatistic analysis were developed and processed in the following order:

- Download the ArcMap application of ArcGIS;

- Download themed layers using the Add Data button in the ArcMap application;

- verification of space data based on the state coordinate system, activating the boundaries of the territory; 


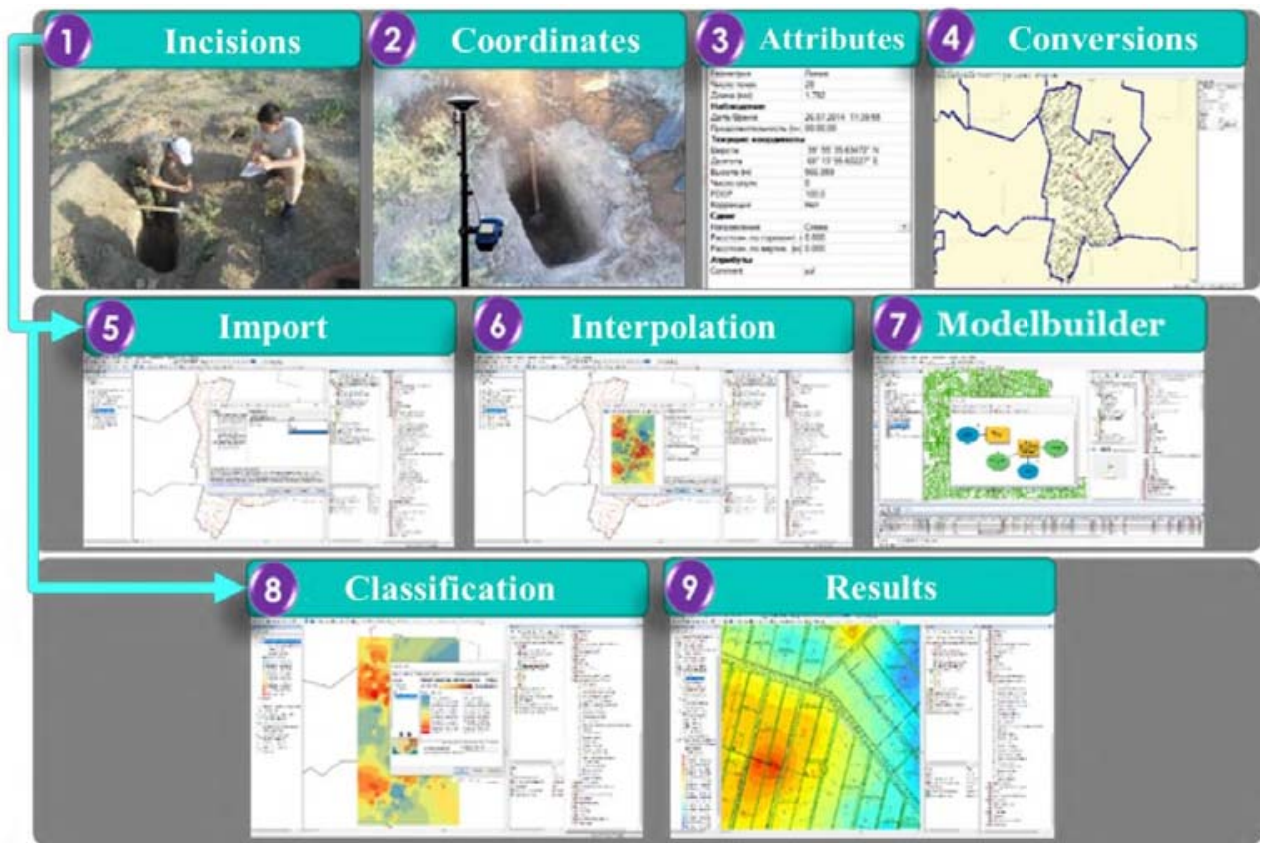

Fig. 2. Methodology of integration of information on soil quality index score into geodata.

- digitization of attributive data on soil quality identified on site based on field research results;

- linking a thematic layer called territorial boundaries to a thematic layer called soil qualities;

- classification of data on soil quality using the geostatistical analysis command (Fig. $3)$;

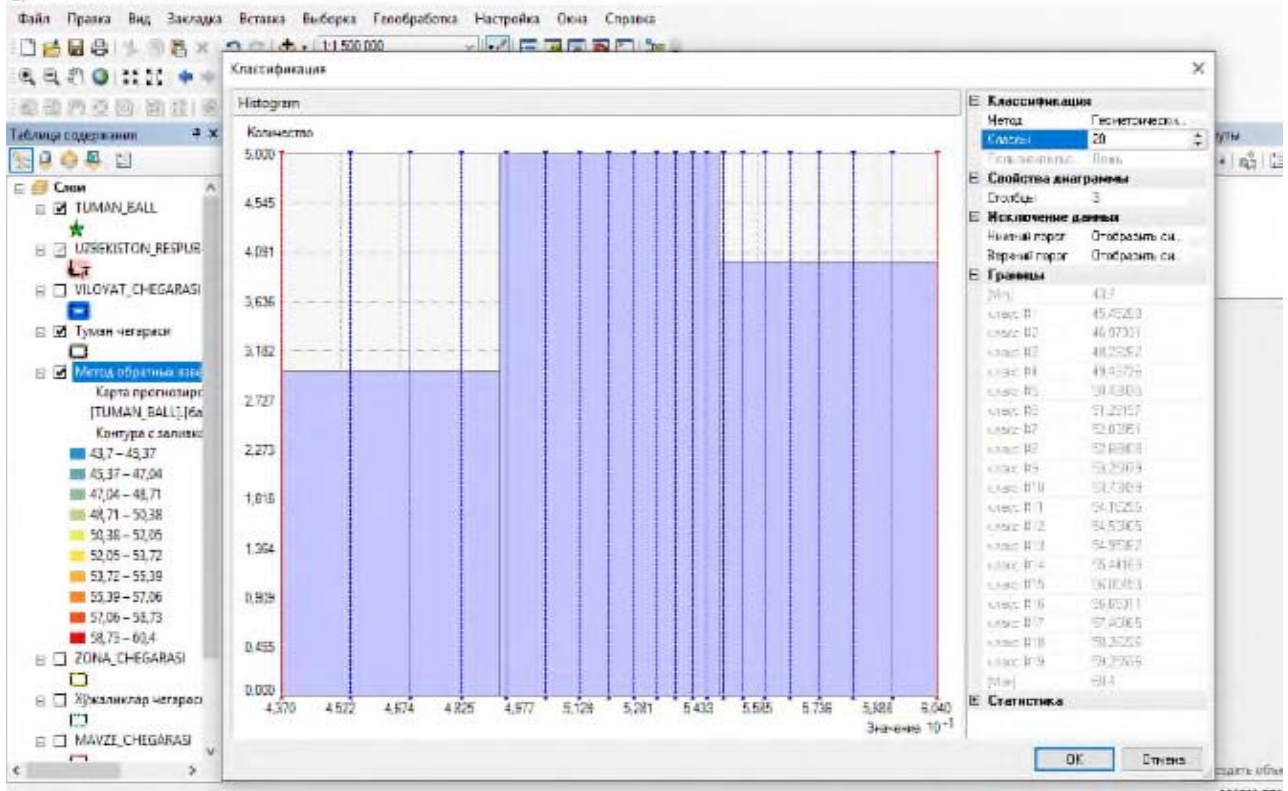

Fig. 3. Classification of soil allotments. 
- based on the value of the selected data indicators, the program automates the visualization in the form of cartographic quality colors;

- visualization of statistical data of stages performed in the process of geostatistical analysis;

- visualization of the result of the work performed in the geostatistical analysis window with a scale of values;

- as a result of the analysis, development of a geostatistical analytical histogram of soil qualities by provinces.

Geostatic analysis was performed in the ArcMap application of the ArcGIS program based on the agrochemical cartogram attribute data of land contours. The results were divided into RGB (R-Red, G-Green, B-Blue) classes by the quality color method and visualized in the order shown in Fig. 4 using cartographic imaging methods.

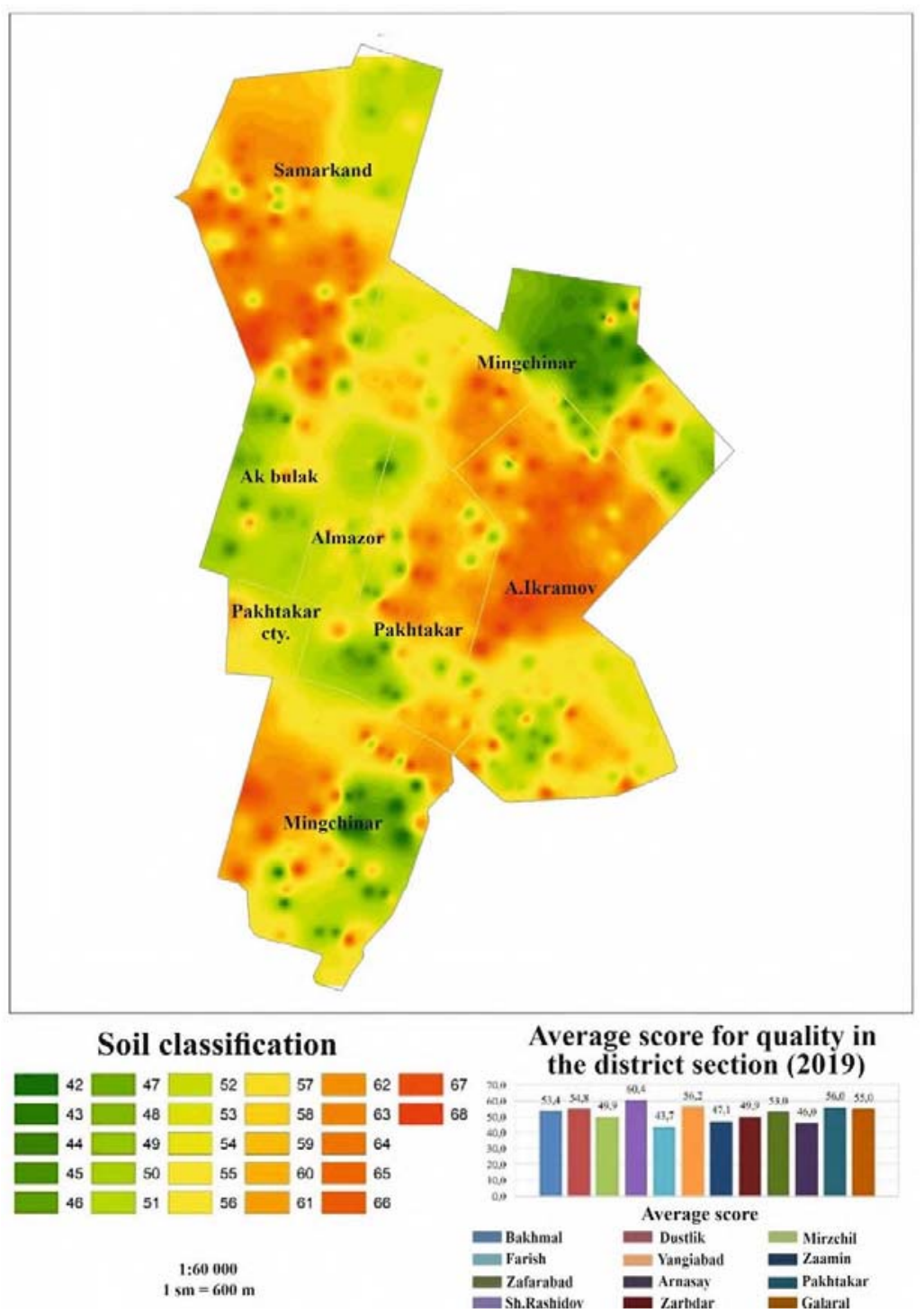

Fig. 4. Soil quality scheme of Pakhtakor district of Jizzakh province. 
The classification shown in Fig. 4 represents the visualization of soil layers with quality colors in a geographic database. For example, it is visualized that soil layers with a fertility of 42 points change to dark green and soil layers with a fertility of up to 68 points change to dark red.

\section{Conclusions}

The scientific basis for the calculation of quality indicators of agricultural lands was analyzed and the following conclusions were drawn.

1. Remote zoning of the land was carried out using satellite imagery and remote control devices to monitor agricultural land and keep records of arable land. As a result, the issues of updating electronic digital maps of agriculture and mapping of crops have been resolved. Field research has been integrated into electronic digital maps to determine the quality of agricultural land and introduce soil quality indices.

2. The results of soil assessment were visualized using geo-information system technologies and electronic digital cards with soil allotments and crop types, as well as explanations on these cards were created at a scale of 1:10000 for existing cotton and grain farms in each district of Jizzakh province, at a scale of 1:10000 for regional (district) land resources and state cadastre departments (divisions) of farming unions. On the basis of soil maps, soil assessments were conducted for each farm and the quality soil quality indices of each land allotment were determined. As a result, the areas of irrigated soils of these districts were determined according to the average soil quality index scores and cadastral groups.

\section{References}

1. A. Inamov, I. Ruziev, S. Nurjanov, IOP Conf. Ser.: Mater. Sci. Eng., 030(1), 012112 (2021)

2. V. Nilipovskiy, A. Inamov, International Multidisciplinary Scientific Geo-Conference Surveying Geology and Mining Ecology Management, 343-350 (2020)

3. B. B. Xakimov, A. N. Inamov, B. A. Allanazarov, International Journal of Advanced Research in Science, Engineering and Technology, 6(11), 11538-11543 (2019)

4. D. W. Allen, Getting to know ArcGIS model builder, 380 (ESRI Press, California, 2011)

5. Y. Peng, F. Li, N. Xu, R. Kulmatov, K. Gao, G. Wang, Y. Zhang, Y. Qiao, Y. Li, H. Yang, S. Hao, Q. Li, S. Khasanov, Chinese Journal of Eco-Agriculture, 29(2), 312-324 (2021)

6. B. Alikhanov, S. Alikhanova, R. Oymatov, Z. Fayzullaev, A. Pulatov, IOP Conf. Ser.: Mater. Sci. Eng., 883(1), 012088 (2020)

7. Y. Ten, R. Oymatov, K. Khayitov, G. Saydalieva, U. Nulloev, I. Nematov, E3S Web Conf., 227, 04004 (2021)

8. I. Musaev, A. Bokiev, M. Botirova, E3S Web Conf., 227, 05004 (2021)

9. A. Jumanov, S. Khasanov, A. Tabayev, G. Goziev, U. Uzbekov, E. Malikov, IOP Conf. Ser.: Earth Environ. Sci., 614(1), 012150 (2020)

10. N. Sabitova, O. Ruzikulova, I. Aslanov, E3S Web Conf., 227, 03003 (2021)

11. R. Kulmatov, A. Taylakov, S. Khasanov, Environ. Sci. Pollut. Res., 28(10), 12245 $12255(2021)$ 
12. S. Isaev, S. Khasanov, Y. Ashirov, T. Karabaeva, A. Gofirov, E3S Web Conf., 244, 02012 (2021)

13. N. Sabitova, O. Ruzikulova, I. Aslanov, E3S Web Conf., 227, 03003 (2021) 